\title{
Executive function in obsessive compulsive disorder at Zagazig University Hospitals: a case-control study
}

\author{
Amira Mohamed Youssef ${ }^{*}$, Wa-il AbouHendy ${ }^{\dagger}$, Amany Elshabrawy ${ }^{\dagger}$ and Shimaa Ibrahim Amin $^{\dagger}$
}

\begin{abstract}
Background: Executive function (EF) domain deficits which most reported include in particular set shifting and inhibition, which are considered main deficits in obsessive-compulsive disorder (OCD). So, this research aimed to assess EF in patients with a primary diagnosis of OCD in comparison to a healthy control group; in order to understand the impaction of this disorder on the patient's neuropsychological status.

Results: There was no significant difference between OCD patients and controls regarding demographic characteristics. Average duration of illness in OCD group was $3.97 \pm 5.08$ years. Forty patients (60.6\%) had OCD medication prior to the study. Depression was the most prevalent comorbidity among OCD group (36.4\%) then anxiety (12.1\%) and social anxiety (3\%). Regarding WCST indices, a significant difference $(P<0.05)$ was found between both groups in total number of correct answers, total number of errors, mean of errors, total number of perseverative errors, mean of perseverative errors, total number of non-perseverative errors, mean of nonperseverative errors, and conceptual level responses without significant difference $(P \geq 0.05)$ in the remaining indices. In ToL indices, there was highly significant difference $(P<0.001)$ between both groups regarding total time, but not regarding total moves $(P \geq 0.05)$. The defect in EF was positively correlated to the severity of symptoms of OCD. There was no significant difference between patients who had been receiving medical treatment and those who had not, also between patients who had comorbidities accompanying OCD and those who had not regarding EF as evident by both WCST measured parameters and TOL parameters.
\end{abstract}

Conclusions: OCD patients appear to have EF deficits in the fields of set-shifting, inhibitory control, working memory, and planning ability.

Keywords: Executive function, Obsessive compulsive, Behavior

\section{Background}

Behavior has been regulated and guided through a constantly changing environment; the brain requires a central coordinating system. The executive system (ES) is responsible for the simultaneous operation of a number of cognitive processes in charge of goal-directed, task-oriented behaviors, self-regulation, and behavior inhibition as well

\footnotetext{
* Correspondence: amira76@doctor.com

tWa-il AbouHendy, Amany Eshabrawy and Shimaa Ibrahim Amin contributed equally to this work.

Psychiatry Department, Faculty of Medicine, Zagazig University, Zagazig, Egypt
}

as planning, working memory, mental flexibility, response inhibition, impulse control, and monitoring of action. Executive function (EF) refers to the many skills required to prepare for and execute complex behaviors [1].

Executive function (EF) is typically considered to comprise a broad category of "higher order" or "supervisory," cognitive skills whose role is to control and coordinate other more basic cognitive functions like language, memory, and visuospatial ability. In this consideration, $\mathrm{EF}$ is "general purpose control mechanisms that modulate the operation of various cognitive sub-processes and thereby regulate the dynamics of human cognition." EFs

\section{Springer Open}

(c) The Author(s). 2020 Open Access This article is licensed under a Creative Commons Attribution 4.0 International License, which permits use, sharing, adaptation, distribution and reproduction in any medium or format, as long as you give appropriate credit to the original author(s) and the source, provide a link to the Creative Commons licence, and indicate if changes were made. The images or other third party material in this article are included in the article's Creative Commons licence, unless indicated otherwise in a credit line to the material. If material is not included in the article's Creative Commons licence and your intended use is not permitted by statutory regulation or exceeds the permitted use, you will need to obtain permission directly from the copyright holder. To view a copy of this licence, visit http://creativecommons.org/licenses/by/4.0/. 
include capacities for planning, initiating, sequencing, and monitoring complex goal-directed behavior [2].

Deficits of EF are present in a wide range of psychiatric disorders. Executive deficits negatively affect everyday functioning and contribute to diminished quality of life in many clinical populations. Consequences of executive deficits may include increased interpersonal conflict, decreased academic achievement, and risk-taking behavior [3].

An impairment in EF will necessarily affect a person's behavior in everyday life, by limiting his/her ability to adjust to environmental demands or changes. In neuropsychological studies, impairments in EF have been linked to damage to or dysfunction of the prefrontal cortex and the disruption of frontosubcortical pathways [4].

Obsessive-compulsive disorder (OCD) is a neuropsychiatric disorder involving distressing intrusive thoughts and related compulsive behaviors. OCD is characterized by repetitive thoughts, images, and behaviors that are distressing and debilitating for sufferers. OCD has a prevalence of 2 to $3 \%$ in the general population [5].

OCD patients show dysfunctions in executive domains, particularly in cognitive inhibition which may give problems when responding to both internal and external requirements, by inhibiting the ability to manage and orient the necessary cognitive resources [6].

Moreover, poorer visuospatial construction in earlyonset OCD was correlated with a larger left middle frontal gyrus volume. Impaired visuospatial memory in people with early-onset $\mathrm{OCD}$ and cognitive inflexibility in people with late-onset OCD were correlated with increased and decreased volume in the left middle frontal gyrus, respectively [7].

Considerable evidence has indicated neurocognitive impairment in patients with OCD [5]. However, which specific functions are involved is still a matter of debate. The EF domain deficits which most reported include in particular set shifting and inhibition, which are considered main deficits in OCD. Deficits have been less reported in other domains like planning, spatial working memory, decision-making, attention, and speed of processing [8].

Therefore, the current research aimed to assess EF in patients with a primary diagnosis of OCD in comparison to a healthy control group; in order to understand the impaction of this disorder on the patient's neuropsychological status.

\section{Methods}

\section{Study design and setting}

A case-control study was conducted in the outpatient clinics of Neuropsychiatry Department, Zagazig University Hospital, during the period from October 2017 to October 2018.

\section{Study participants}

They were classified into two groups:

- OCD group

This group included 66 patients were clinically diagnosed with OCD as their main symptom.

Inclusion criteria:

- All patients should meet the Diagnostic and Statistical Manual of Mental Disorders V (DSM-V) criteria for OCD [9].

- Patients should have no coexisting brain damage or mental retardation.

- Both sexes are included.

- Age ranging from 18 to 60 years old.

- Exclusion criteria:

- Age below 18 or above 60 years old.

- Patients who fulfilled DSM-V criteria for mental retardation, organic brain disease, severe physical disorders, history of drug/alcohol dependence.

- Healthy control group (HCG)

This group included 35 apparently healthy controls.

- Sample size and technique:

Assuming that the mean of the trail test time in HCG $=58.9 \pm 22.95$ and the mean of the trail test time in OCD group $=75.95 \pm 26.81$ [8] while confidence interval is $95 \%$ and power is 80 in OpenEpi, then sample size $=101$ (66 OCD patients and 35 controls). Systematic random sampling technique was adopted for selection of the participants.

\section{Tools and operational steps}

Patients were subjected to:

A semi-structured interview was employed to obtain socio-demographic information of patients (age, sex, education, marital status, occupation, residence, and substance use) and clinical characteristics of the disorder (age of onset of disorder, duration of the disorder, compliance to treatment, family history of psychiatric disorders, and medical history of patients).

Psychometric assessment was done by

\section{Structured Clinical Interview for DSM-V (SCID) [9]}

The SCID5 is organized into diagnostic modules, and it assesses mood disorders, psychotic disorders, substance use disorders, anxiety disorders, obsessive-compulsive and related disorders, eating disorders, somatic symptom disorders, some sleep disorders, "externalizing disorders" and trauma, and stressor-related disorders. It has been 
published in various forms, including a version for clinicians (SCID-CV) and a version for clinical trials (SCID$\mathrm{CT})$.

Yale-Brown Obsessive Compulsive Scale (YBOCS) [10] Arabic version translated by Ain Shams Institute of Psychiatry. The Y-BOCS is used to estimate the severity of symptoms of OCD. The scale is used extensively in the field of research and clinical practice to asses both the severity of OCD obsessions and compulsions without being biased to the type of their content and the improvement during treatment. This scale measures obsessions and compulsions separately. The scale is self-rating, which consists of 10 items, the results can be calculated according to the total score: $0-7$ is subclinical; $8-15$ is mild; $16-$ 23 is moderate; $24-31$ is severe; and $32-40$ is extreme.

\section{Obsessive Compulsive Symptoms Scale (OCSA) [11]}

This self-rating scale consists of a group of questions (statements) (83) divided into subgroups, and each subgroup tests a dimension of obsession (e.g., ruminations ) and/or compulsions (e.g., religious compulsions) this scale was used to compare the severity of obsessions and compulsions between the two groups. This scale is suitable and applicable for Arabic cultures. The total degree ranges from 31 to 85 .

EF assessment was done using a battery of tests to assess different domains of EFs, chosen from the Psychology Experiment Building Language (PEBL). Namely, the tests used were

\section{Wisconsin Card Sorting Test (WCST) [12]}

Is one of the classic tests of prefrontal cortex function. Each card in this test can be sorted by color, shape, or number. The task for the participant is to deduce the correct sorting criterion on the basis of feedback and to flexibly switch sorting rules whenever he/she is given feedback that the sorting criterion has changed. It consists of two groups of cards: 4 stimulus cards and 64 reaction cards. Each card includes different colors and numbers of signs. The test administrator asks the subject to match each card from the group with a stimulus card. Correctly matched cards are arranged according to color, sign, and number categories. When the subject performs 10 consecutive correct matches in one category (for instance, matching colors), the matching rule is shifted to another category. After each reaction, the subject is provided with feedback about whether his/her response was correct or not, but is not given information on the correct match category. When the subject finishes all cards from the reaction card group the test is terminated

\section{Tower of London Test (ToL) [13]}

In clinical and experimental neuropsychology, planning ability is assessed most often using the Tower of London (ToL) task or one of its variants. In ToL task, the classic version of the ToL consists of three differently colored balls placed on three vertical rods of different heights that may hold at maximum either one, two or three balls, respectively. In most computerized versions of ToL, start state and goal state are presented in the lower and upper part of the screen, respectively. Subjects are asked to transform the start state to match the goal state while following three rules: (a) only one ball could be moved at a time; (b) a ball may not be moved if another ball was already on top of it; and (c) three balls could be accommodated at the tallest peg on the left, two balls at the peg in the middle, and one ball at the smallest peg on the right. The examiner should place great emphasis on planning ahead the solution before actually moving the balls. Subjects should be asked to complete the task as quickly and accurately as possible.

\section{Statistical analysis}

The collected data were coded, entered, presented, and analyzed by computer using a data base software program, Statistical Package for Social Science (version 21, SPSS Inc., Chicago, IL). Quantitative variables were expressed as the mean \pm standard deviation (SD) while the qualitative variables were expressed as a number and percentage. For quantitative variables, Independent samples $t$ test $(t)$ and one-way analysis of variance (ANOVA) were used as appropriate for normally distributed data after testing the normality with Levene's test. Chi-square test was used to detect the relation between different qualitative variables. The results were considered statistically significant and highly statistical significant when the significant probability ( $P$ value) was $<0.05^{*}$ and $<0.001^{* * *}$, respectively.

\section{Results \\ Demographic and clinical caractristics}

A total of 101 participants were included in the current study and divided into 66 OCD patients and 35 healthy controls with no statistically significant difference $(P \geq$ $0.05)$ between them regarding demographic characteristics; ensuring homogeneity of both groups. Mean age of HCG was $27.4 \pm 3.58$ years, while mean age for OCD group was $29.03 \pm 8.08$ years. Both groups included a total of 48 females (47.5\%) and 53 males (52.5\%). Fiftythree participants $(52.5 \%)$ were single; while 48 participants $(47.5 \%)$ were married. Ninety-three participants (92.1\%) had higher education; while 8 of them (7.9\%) had medium education (Table 1).

Average duration of illness in OCD group was $3.97 \pm$ 5.08 years. Forty patients $(60.6 \%)$ had OCD medication prior to the study, while 26 of them (39.4\%) had not. 
Table 1 Demographic characteristics of the studied participants $(n=101)$

\begin{tabular}{llll}
\hline & HCG $(n=35)$ & OCD $(n=66)$ & $P$ value \\
\hline Age (years) & & & \\
mean \pm SD & $27.40 \pm 3.58$ & $29.03 \pm 8.08$ & ${ }^{a} 0.094$ \\
Range & $(24-32)$ & $(20-48)$ & \\
Sex, no (\%) & & & \\
Female & $20(57.1 \%)$ & $28(42.4 \%)$ & ${ }^{\mathrm{b}} 0.461$ \\
$\quad$ Male & $15(42.9 \%)$ & $38(57.6 \%)$ & \\
$\begin{array}{l}\text { Marital status, no (\%) } \\
\text { Single }\end{array}$ & $11(31.4 \%)$ & $42(63.6 \%)$ & \\
$\quad$ Married & $24(68.6 \%)$ & $24(36.4 \%)$ & \\
Education, no (\%) & & & \\
Medium & $0.0(00 \%)$ & $8(12.1 \%)$ & \\
Higher & $35(100 \%)$ & $58(87.9 \%)$ & \\
\hline
\end{tabular}

HCG health control group, OCD obsessive compulsive disorder group, $S D$ standard deviation

andependent $t$ test

${ }^{\mathrm{b}}$ Chi-square test $\left(x^{2}\right)$

Depression was the most prevalent comorbidity among OCD group (36.4\%) followed by anxiety (12.1\%) and social anxiety (3\%). There was no statistically significant difference $(P \geq 0.05)$ between males and females of OCD group regarding these variables (Table 2 ).

\section{Executive functions test results}

WCST was used to compare the performance of HCG and OCD group, three indices were measured regarding test categories: categories completed, categories experienced, and trials to complete first category. There was no statistically significant difference $(P \geq 0.05)$ between both groups regarding these indices (Table 3 ).

Six indices were measured regarding response type: correct responses, errors, perseverative responses, perseverative errors, non-perseverative errors, and unique errors. The total number and the mean of each index were compared for both groups. A statistically significant difference $(P<$ 0.05 ) was found between both groups in the following indices: total number of correct answers, total number of errors, mean of errors, total number of perseverative errors, mean of perseverative errors, total number of non-perseverative errors, and mean of non-perseverative errors. No significant difference $(P \geq 0.05)$ was found between both groups regarding the remaining indices (Table 3 ).

Three other indices were calculated: Failure to maintain set, Learning to learn and conceptual level responses. A statistically significant difference $(P<0.05)$ was found between both groups in conceptual level responses. No significant difference $(P \geq 0.05)$ was found between both groups regarding the remaining indices (Table 3 ).

ToL was used to compare the performance of HCG and OCD group, two indices were measured: Total moves and total time. There was highly statistical significant difference $(P<0.001)$ between both groups regarding total time, but not regarding total moves $(P \geq 0.05)$ (Table 4$)$.

The relation between OCD symptoms severity and EF revealed statistically significant difference $(P<0.05)$ in the following parameters: total number of correct answers, total number of errors, mean number of errors, total and mean of perseverative errors, trials to complete first category, learning to learn $(P=0.003)$, total moves and highly statistical significant difference $(P<0.001)$ regarding total time (Table 5).

On assessing medical treatment among OCD group, there was no statistically significant difference $(P \geq 0.05)$ between patients who had been receiving medical treat accompanying OCD and those who had not regarding EF as evident by both WCST measured parameters and TOL parameters (Table 6).

Also, there was no statistically significant difference $(P$ $\geq 0.05$ ) between patients who had comorbidities accompanying OCD and those who had not regarding EF as

Table 2 Clinical characteristics of the OCD group $(n=66)$

\begin{tabular}{llll}
\hline & Female $(n=28)$ & Male $(n=38)$ & Total $(n=66)$ \\
\hline $\begin{array}{l}\text { Duration of OCD (years) } \\
\text { mean } \pm \text { SD }\end{array}$ & $4.36 \pm 1.00$ & $3.68 \pm 1.00$ & $3.97 \pm 5.08$ \\
$\begin{array}{l}\text { Treatment, no (\%) } \\
\text { No }\end{array}$ & $10(35.7 \%)$ & $16(42.1 \%)$ & \\
Yes & $18(64.3 \%)$ & $22(57.9 \%)$ & $26(39.4 \%)$ \\
Comorbidity, no (\%) & $14(50 \%)$ & & $40(60.6 \%)$ \\
None & $10(35.7 \%)$ & $18(47.4 \%)$ & $32(48.5 \%)$ \\
Depression & $4(14.3 \%)$ & $14(36.8 \%)$ & $24(36.4 \%)$ \\
Anxiety & $0.0(00 \%)$ & $4(10.5 \%)$ & $8(12.1 \%)$ \\
Social anxiety & $2(5.3 \%)$ & $2(3 \%)$ \\
\hline
\end{tabular}

$O C D$ obsessive compulsive disorder group, $S D$ standard deviation

${ }^{\mathrm{a}}$ Independent $t$ test

${ }^{\mathrm{b}}$ Chi-square test $\left(x^{2}\right)$ 
Table 3 WCST indices (categories, response type, others) among the studied participants $(n=101)$

\begin{tabular}{|c|c|c|c|}
\hline & $\begin{array}{l}\text { HCG }(n=35) \\
\text { mean } \pm \text { SD }\end{array}$ & $\begin{array}{l}\mathrm{OCD}(n=66) \\
\text { mean } \pm \text { SD }\end{array}$ & ${ }^{a} P$ value \\
\hline \multicolumn{4}{|l|}{ Categories } \\
\hline Categories completed & $4 \pm 1.23$ & $3.36 \pm 1.41$ & 0.347 \\
\hline Categories experienced & $4.80 \pm 1.10$ & $4.24 \pm 1.37$ & 0.392 \\
\hline Trials to complete 1st category & $14.80 \pm 9.63$ & $14.88 \pm 7.41$ & 0.983 \\
\hline \multicolumn{4}{|l|}{ Response type } \\
\hline Correct (T) & $54.40 \pm 4.16$ & $45.79 \pm 9.04$ & $0.045^{*}$ \\
\hline Correct (M) & $11.75 \pm 2.31$ & $11.61 \pm 3.25$ & 0.925 \\
\hline Errors (T) & $9.60 \pm 4.16$ & $18.21 \pm 9.04$ & $0.045^{*}$ \\
\hline Errors (M) & $2.33 \pm 1.88$ & $6.23 \pm 7.39$ & $0.017^{*}$ \\
\hline Perseverative responses $(T)$ & $19.20 \pm 2.28$ & $20.79 \pm 8.15$ & 0.671 \\
\hline Perseverative responses (M) & $5.63 \pm 2.73$ & $8.20 \pm 8.67$ & 0.519 \\
\hline Perseverative errors $(T)$ & $6.60 \pm 2.61$ & $11.42 \pm 7.76$ & $0.015^{*}$ \\
\hline Perseverative errors (M) & $2.14 \pm 1.89$ & $5.72 \pm 8.65$ & $0.047^{*}$ \\
\hline Non-perseverative errors $(T)$ & $3.00 \pm 2.00$ & $6.91 \pm 6.55$ & $0.014^{*}$ \\
\hline Non-perseverative errors (M) & $0.75 \pm 0.73$ & $2.26 \pm 3.04$ & $0.023^{*}$ \\
\hline Unique errors $(T)$ & $1.00 \pm 1.00$ & $2.21 \pm 4.50$ & 0.556 \\
\hline Unique errors (M) & $0.23 \pm 0.21$ & $0.84 \pm 2.19$ & 0.540 \\
\hline \multicolumn{4}{|l|}{ Others } \\
\hline Failure to maintain set & $0.60 \pm 0.89$ & $0.70 \pm 1.49$ & 0.914 \\
\hline Learning to learn & $2.81 \pm 3.26$ & $4.06 \pm 6.12$ & 0.665 \\
\hline Conceptual level responses & $50.20 \pm 4.55$ & $40.52 \pm 12.37$ & $0.005^{*}$ \\
\hline
\end{tabular}

WCST Wisconsin Card Sorting Test, HCG health control group, OCD obsessive compulsive disorder group, $T$ total number, $M$ mean of each index, SD standard deviation

andependent $t$ test

*Significant $(P<0.05)$

evident by both WCST measured parameters and TOL parameters (Table 7).

\section{Discussion}

The study at hand found many indices to be statistically significantly different between HCG and OCD group, regarding both WCST and ToL. These indices denote that EF deficits are in fact related to OCD.

In WCST, namely, total number of perseverative errors, means number of perseverative errors, total number of non-perseverative errors, and means numbers of non-perseverative errors were found to be significantly

Table 4 ToL indices among the studied participants $(n=101)$

\begin{tabular}{|c|c|c|c|}
\hline & $\begin{array}{l}\mathrm{HCG}(n=35) \\
\text { mean } \pm \mathrm{SD}\end{array}$ & $\begin{array}{l}\text { OCD }(n=66) \\
\text { mean } \pm \text { SD }\end{array}$ & ${ }^{a} P$ value \\
\hline Total moves & $165.40 \pm 29.87$ & $182.15 \pm 28.82$ & 0.236 \\
\hline Total time & $587.62 \pm 112.43$ & $948.96 \pm 410.46$ & $<0.001^{* *}$ \\
\hline
\end{tabular}

different and were most important in interpretation of EF deficits. Higher perseverative errors in the OCD group denote failure of set shifting, while higher nonperseverative errors could indicate rapid loss of information learnt during the previous trials in the course of the test; denoting problems with working memory.

Sanz et al. stated that the most consistent finding across the studies in OCD was the deficit in tasks involving shifting in cognitive set. The cognitive operations needed to perform the WCST, searching for a new category and the consolidation of the correct classification category, were closely related to shifting cognitive set [14].

In ToL, only the total time, but not the total number of moves, was found to be statistically significantly different between HCG and OCD group, which could indicate a milder form of impairment in planning ability, response inhibition, and reasoning.

Abramovitch and Cooperman reported similar to the present results that there was significant difference in planning ability between healthy individuals and OCD individuals; being reduced in the latter, as 
Table 5 Relation between OCD symptoms severity and EF according to YBOCD score among OCD group $(n=66)$

\begin{tabular}{|c|c|c|c|c|c|c|c|}
\hline & \multicolumn{6}{|c|}{ OCD group $(n=66)$} & \multirow[t]{3}{*}{${ }^{\text {a }} P$ value } \\
\hline & \multicolumn{2}{|l|}{$\overline{\text { Mild }}$} & \multicolumn{2}{|c|}{ Moderate } & \multicolumn{2}{|l|}{ Severe } & \\
\hline & Mean & SD & Mean & SD & Mean & SD & \\
\hline \multicolumn{8}{|l|}{ WCST parameters } \\
\hline Categories completed & 3.63 & 1.24 & 3.67 & 0.84 & 2.83 & 1.71 & 0.072 \\
\hline Categories experienced & 4.42 & 1.18 & 4.56 & 0.86 & 3.83 & 1.71 & 0.168 \\
\hline Trials to complete firstst category & 49.33 & 5.02 & 47.89 & 6.33 & 41.96 & 11.49 & $0.008^{*}$ \\
\hline Correct $(\mathrm{T})$ & 11.73 & 2.26 & 10.64 & 0.92 & 12.57 & 4.73 & 0.164 \\
\hline Correct (M) & 14.67 & 5.02 & 16.11 & 6.33 & 22.04 & 11.49 & $0.008^{*}$ \\
\hline Errors $(T)$ & 3.87 & 2.34 & 3.94 & 2.52 & 9.92 & 10.82 & $0.004^{*}$ \\
\hline Errors (M) & 20.21 & 3.71 & 19.67 & 5.22 & 22.75 & 11.94 & 0.398 \\
\hline Perseverative responses $(T)$ & 6.75 & 3.08 & 5.93 & 2.25 & 11.64 & 13.37 & 0.054 \\
\hline Perseverative responses (M) & 8.50 & 3.20 & 9.78 & 3.75 & 15.54 & 10.90 & $0.003^{*}$ \\
\hline Perseverative errors ( $(T)$ & 3.07 & 2.13 & 3.03 & 1.53 & 10.42 & 12.91 & $0.003^{*}$ \\
\hline Perseverative errors (M) & 6.17 & 3.12 & 6.33 & 5.92 & 6.83 & 7.97 & 0.924 \\
\hline Non perseverative errors ( $\mathrm{T}$ ) & 1.67 & 1.22 & 1.65 & 2.11 & 2.88 & 4.21 & 0.256 \\
\hline Non perseverative errors (M) & 0.92 & 1.06 & 1.89 & 2.19 & 3.33 & 6.81 & 0.158 \\
\hline Unique errors (T) & 0.26 & 0.36 & 0.48 & 0.71 & 1.54 & 3.43 & 0.094 \\
\hline Unique errors (M) & 15.88 & 5.98 & 15.78 & 9.01 & 11.83 & 1.31 & $0.038^{*}$ \\
\hline Failure to maintain set & 0.63 & 0.82 & 0.33 & 0.49 & 1.25 & 3.04 & 0.284 \\
\hline Learning to learn & 0.00 & 3.11 & 6.89 & 6.67 & 4.77 & 6.21 & $0.003^{*}$ \\
\hline Conceptual level responses total & 44.25 & 8.19 & 43.33 & 8.33 & 36.21 & 16.06 & 0.117 \\
\hline \multicolumn{8}{|l|}{ ToL parameters } \\
\hline Total moves & 174.42 & 18.85 & 174.00 & 30.14 & 200.54 & 26.55 & $0.010^{*}$ \\
\hline Total time & 721.38 & 231.50 & 787.42 & 185.84 & 1326.67 & 412.66 & $<0.001^{* *}$ \\
\hline YBOCD & 12.13 & 2.40 & 18.22 & 1.73 & 27.46 & 2.57 & $<0.001^{* *}$ \\
\hline
\end{tabular}

WCST Wisconsin Card Sorting Test, ToL Tower of London Test, YBOCS Yale-Brown Obsessive Compulsive Scale, OCD obsessive compulsive disorder group, $T$ total number, $M$ mean of each index, $S D$ standard deviation

${ }^{a}$ One-way ANOVA test

*Significant $(P<0.05)$

**Highly significant difference $(P<0.001)$

measured by excessive moves in ToL and Tower of Hanoi (ToH) tests [15].

Also, in consistency with the current study, the study of Bouvard et al., in which the Behavior Rating Inventory of Executive Function Adult (BRIEF-A) was used to measure executive dysfunction in everyday life in people with OCD, their results confirmed the impairment of EF for patients with OCD [16].

Goncalves et al. reported poor performance in both attentional set shifting and task-switch situations in individuals with OCD in comparison to healthy individuals. This was evident by significantly more errors by OCD individuals [17].

Page et al. concluded that there was consistent evidence that OCD patients tend to decrease their working memory performance with increase task load [18].

In addition, the study of Pedroliet al. involved 58 participants (29 OCD patients and 29 controls) and showed a clear difference was found between OCD patients and the control group, particularly in EF [6].

It is however worth mentioning that, in the current study, not all indices were statistically significantly different between the individuals of both groups, which can shed some light on the wide variations and inconsistency in literature regarding EF deficits in OCD patients; the types, magnitude, and underlying pathology. This might be due to the fact that there's a wide range of EF tests with wide range of calculated indices of which the application and interpretation can differ between researchers in literature.

For example, Shin et al. reported that patients with OCD appear to have broad, albeit not severe, EF deficits. Although the magnitude of the deficits was, in general, not large, visuospatial memory, visual organizational skill and, in accordance with the present results, planning ability appear to be the most impaired areas in patients 
Table 6 Comparison of WCST and ToL parameters regarding medical treatment among OCD group $(n=66)$

\begin{tabular}{|c|c|c|c|c|c|}
\hline & \multicolumn{4}{|c|}{ OCD group $(n=66)$} & \multirow[t]{3}{*}{$P$ value } \\
\hline & \multicolumn{2}{|c|}{ Non medicated $(n=26)$} & \multicolumn{2}{|c|}{ Medicated $(n=40)$} & \\
\hline & Mean & SD & Mean & SD & \\
\hline \multicolumn{6}{|l|}{ WCST parameters } \\
\hline Categories completed & 2.91 & 1.640 & 3.58 & 1.261 & 0.220 \\
\hline Categories experienced & 3.82 & 1.60 & 4.47 & 1.22 & 0.216 \\
\hline Trials to complete 1st category & 43.18 & 10.36 & 47.63 & 8.19 & 0.204 \\
\hline Correct $(T)$ & 12.79 & 4.77 & 11.12 & 2.13 & 0.292 \\
\hline Correct (M) & 20.82 & 10.36 & 16.37 & 8.19 & 0.204 \\
\hline Errors (T) & 8.93 & 10.85 & 4.77 & 4.78 & 0.251 \\
\hline Errors (M) & 22.55 & 12.25 & 20.00 & 5.43 & 0.526 \\
\hline Perseverative responses (T) & 10.75 & 13.69 & 7.03 & 4.82 & 0.402 \\
\hline Perseverative responses (M) & 15.82 & 11.50 & 9.21 & 3.82 & 0.091 \\
\hline Perseverative errors (T) & 10.12 & 13.76 & 3.56 & 3.15 & 0.149 \\
\hline Perseverative errors (M) & 5.36 & 3.56 & 7.16 & 7.39 & 0.379 \\
\hline Non perseverative errors ( $T$ ) & 1.79 & 1.48 & 2.37 & 3.67 & 0.551 \\
\hline Non perseverative errors (M) & 1.09 & 1.51 & 2.84 & 5.63 & 0.214 \\
\hline Unique errors ( $T$ ) & 0.45 & 0.53 & 1.08 & 2.84 & 0.360 \\
\hline Unique errors (M) & 14.91 & 5.82 & 14.00 & 6.86 & 0.715 \\
\hline Failure to maintain set & 1.45 & 3.24 & 0.37 & 0.60 & 0.295 \\
\hline Learning to learn & 4.90 & 6.09 & 3.99 & 6.64 & 0.777 \\
\hline Conceptual level responses total & 2.91 & 1.640 & 3.58 & 1.261 & 0.220 \\
\hline \multicolumn{6}{|l|}{ ToL parameters } \\
\hline Total moves & 187.82 & 29.755 & 181.68 & 29.469 & 0.588 \\
\hline Total time & 968.43 & 401.36 & 970.99 & 445.47 & 0.988 \\
\hline
\end{tabular}

WCST Wisconsin Card Sorting Test, ToL Tower of London Test, OCD obsessive compulsive disorder group, $T$ total number, $M$ mean of each index, SD standard deviation Independent $t$ test

with OCD. They also reported similarly to the current study that individuals with OCD had been observed to experience difficulties in (1) inhibiting ongoing cognitive and motor responses, (2) shifting attention from one aspect of stimuli to others, (3) engaging in executive planning, and (4) decision-making [5].

Other authors, like Bedard et al., mentioned that patients with $\mathrm{OCD}$ to experience significant impairments in visuospatial memory, verbal memory, verbal fluency, and processing speed, whereas the attentional ability was relatively preserved [19].

Meanwhile, Bannon et al. mentioned that the inconsistency in literature findings at many levels, regarding EF impairments in OCD patients. For example, it was reported by some authors that the most consistent finding was a deficit in inhibition and impaired set shifting ability, while planning ability was reported to be unaffected. Inconsistent findings had been observed for working memory and verbal fluency [20].

Similarly, Hosenbocus and Chahal reported that findings on working memory and verbal fluency had also been inconsistent. On the one hand, adolescents with OCD had been reported to have deficits similar to patients with frontal lobe lesions. On the other hand, other authors reported no impairments on several measures of working memory. Similar inconsistencies were reported in children with OCD. Interestingly, some authors reported that children with OCD demonstrated relative strengths in various executive control domains as well as intact memory functioning in comparison to HCG [1].

On the other hand, other neurocognitive conclusions as Bedard et al. tended to be moderate, as impairments might in fact be limited to basic functions such as motor execution and speed of processing [19].

Literature had also revealed mixed findings regarding EF deficits pathophysiology. For example, set shifting and inhibition were considered by some authors as Moritz et al. to represent deficits in core EFs; such that, a deficit of planning measured at the ToL or a low score at the WCST, associated with dorsolateral frontal lesions, might in fact reflect low motor inhibition or poor 
Table 7 Comparison of WCST and ToL parameters regarding comorbidities among OCD group $(n=66)$

\begin{tabular}{|c|c|c|c|c|c|}
\hline & \multicolumn{4}{|c|}{ OCD group $(n=66)$} & \multirow{3}{*}{$\begin{array}{l}\text { a } \\
P \text { value }\end{array}$} \\
\hline & \multicolumn{2}{|c|}{ No comorbidity $(n=34)$} & \multicolumn{2}{|c|}{ Comorbidity $(n=32)$} & \\
\hline & Mean & SD & Mean & SD & \\
\hline \multicolumn{6}{|l|}{ WCST parameters } \\
\hline Categories completed & 3.31 & 1.251 & 3.35 & 1.579 & 0.933 \\
\hline Categories experienced & 4.23 & 1.24 & 4.24 & 1.52 & 0.993 \\
\hline Trials to complete 1st category & 16.15 & 8.68 & 12.94 & 3.63 & 0.178 \\
\hline Correct $(T)$ & 45.85 & 6.54 & 46.12 & 10.91 & 0.937 \\
\hline Correct (M) & 11.44 & 2.50 & 11.95 & 3.97 & 0.686 \\
\hline Errors (T) & 18.15 & 6.54 & 17.88 & 10.91 & 0.937 \\
\hline Errors (M) & 5.22 & 3.73 & 7.12 & 9.74 & 0.511 \\
\hline Perseverative responses (T) & 20.31 & 5.09 & 21.41 & 10.48 & 0.730 \\
\hline Perseverative responses (M) & 7.74 & 5.43 & 8.90 & 11.25 & 0.736 \\
\hline Perseverative errors (T) & 10.62 & 3.95 & 12.41 & 10.25 & 0.555 \\
\hline Perseverative errors (M) & 4.19 & 3.17 & 7.32 & 11.67 & 0.304 \\
\hline Non perseverative errors ( $(T)$ & 7.54 & 5.98 & 5.71 & 6.51 & 0.436 \\
\hline Non perseverative errors (M) & 2.36 & 2.61 & 2.00 & 3.39 & 0.754 \\
\hline Unique errors ( $T$ ) & 2.08 & 2.06 & 2.29 & 5.93 & 0.890 \\
\hline Unique errors (M) & 0.63 & 0.77 & 1.02 & 2.98 & 0.611 \\
\hline Failure to maintain set & 0.31 & 0.63 & 1.12 & 2.62 & 0.234 \\
\hline Learning to learn & 5.93 & 6.40 & 3.00 & 6.28 & 0.307 \\
\hline Conceptual level responses total & 40.23 & 9.40 & 41.06 & 14.64 & 0.860 \\
\hline \multicolumn{6}{|l|}{ ToL parameters } \\
\hline Total moves & 179.85 & 28.717 & 187.06 & 30.072 & 0.512 \\
\hline Total time & 847.08 & 284.05 & 1064.09 & 491.67 & 0.167 \\
\hline
\end{tabular}

WCST Wisconsin Card Sorting Test, ToL Tower of London Test, OCD obsessive compulsive disorder group, $T$ total number, $M$ mean of each index, SD standard deviation

andependent $t$ test

set-shifting capacities, respectively, more closely associated with frontal ventral or caudate involvement [21].

Divergent results from previous studies might be explained by the fact that OCD is a complex disorder with many symptoms and variants.

Regarding the relation between OCD symptoms severity and EF, this study showed that there were significant relation between OCD symptoms severity and EF in some domains.

In consistent with Fournet et al. who revealed positive significant correlations between the measures of OCD severity and BRIEF-A main scores [4]. Also, the results of McNamara et al. who found in children with OCD that impairments in various domains of $\mathrm{EF}$ were predictive of higher mean obsessive compulsive severity scores [22].

Pedron et al. showed that specific impairment of EF was associated with specific obsessive-compulsive symptoms dimensions (e.g., symmetry/ordering, hoarding, contamination/cleaning), the severity of obsessive-compulsive symptoms in those different dimensions significantly correlating with impaired specific EF [23].
This association between EF impairment and symptoms severity could be explained by the frontosubcortical circuitry deficits in OCD, influencing both clinical symptoms and executive dysfunctions, creating a vicious circle [4].

In a large systematic meta-analytic review of correlations between cognitive function and symptom severity in OCD samples. Thirty-eight studies were included; they found a small-to-moderate degree of association between OCD symptom severity and cognitive function [24].

In contrast, Bédard et al. assessed the EF of 40 patients with OCD and did not found correlation between the severity of illness and neuropsychological findings [19]. Similarly, in another study conducted by Airaksinen et al. who mentioned no correlation between neuropsychological test scores and YBOCS scores of patients with OCD [25].

Several studies have suggested significant association between the severity of symptoms and neuropsychological deficits in OCD. However, other studies have 
reported the absence of association between symptoms and neuropsychological test performance [26].

The study at hand also showed that there was no statistically significant difference between patients who had been receiving treatment accompanying OCD and those who had not regarding EF as evident by both WCST measured parameters and TOL parameters.

In consistent with Fournet et al. who revealed an impairment in $\mathrm{EF}$ in the treatment-naïve and relapsed OCD groups, relative to the HCG with no significant difference in EF between the two groups of patients [4].

Authors have argued for the absence of significant effect of medications. A study with large number of drug-naive OCD patients reported significant impairment in tower of London, further supporting the primary nature of deficits and absence of significant effect of medications [27]. On the contrary, few studies have suggested improvement in neuropsychological test performance after treatment with selective serotonin reuptake inhibitors [28].

As regards OCD and comorbidities, the present results showed no statistically significant difference between patients who had comorbidities accompanying OCD and those who had not regarding EF as evident by both WCST measured parameters and TOL parameters.

Only a few studies have specifically examined the effect of depressive symptoms on neuropsychological performance in OCD; one study compared patients with OCD and those with unipolar depression and reported greater cognitive deficits in OCD compared to unipolar depression [29].

In agreement with Abramovitch et al. who examined the relationship between severity of depression and neuropsychological performance. This meta-analysis did not suggest significant relation between depressive symptoms and neuropsychological performance in OCD [30].

Further, evidence for persisting neuropsychological deficits in recovered OCD patients in the absence of depression or anxiety which provides further support to the view that these deficits are primary to OCD and not secondary to depression or other comorbidities [31].

On the other hand, Moritz et al. have found differences in WCST and creative verbal fluency test scores between OCD patients with high Beck Depression Inventory and Hamilton Depression Rating Scale (HAM-D) levels, OCD patients with low Beck Depression Inventory, and HAM$\mathrm{D}$ levels and healthy controls. Executive functions of patients with OCD with low depression levels were found to be similar to those of healthy controls [32].

The limitations of present study included that assessment of EFs using WCST represents some domains of EFs but not all that is why there is an immediate need for uniform assessments in OCD as at present, there are no guidelines or consensus on the tests to be used. Such a consensus cognitive battery could allow cross-cultural comparison of results and could be used in future for multicentric trials for prediction of treatment response. Also, the small sample size may affect our results. Difficulty to identify patients in the clinic without comorbidity and without use of medicines forced us to include those patients on our study. It may be suggested that additional studies are needed, conducted over larger patient groups without comorbidity and use of medicines and where subgroups of disorders are taken into consideration to overcome the existing contradictory results in this field.

\section{Conclusions}

The present study showed that OCD is associated with broad EF impairment, and these deficits cannot be accounted for by co-occurring depression or other co morbidity or being medicated or not, but additional research is needed to determine the causal links between EF impairments and OCD and build a more detailed model of the neurobiology of these impairments. A better understanding of when and how EF impairments arise for individuals with OCD may have a great impaction treatment, such as pharmacological interventions targeting specific aspects of prefrontal function, or training programs to improve EF or teach compensatory strategies to mitigate the effects of EF impairments.

\section{Abbreviations}

ANOVA: Analysis of variance; BRIEF-A: Behavior Rating Inventory of Executive Function Adult; DSM-V: Diagnostic and Statistical Manual of Mental Disorders V; EF: Executive function; ES: Executive system; HAM-D: Hamilton Depression Rating Scale; HCG: Healthy control group; OCD: Obsessive-compulsive disorder; OCSA: Obsessive Compulsive Symptoms Scale; PEBL: Psychology Experiment Building Language; SCID: Structured Clinical Interview for DSM-V; ToH: Tower of Hanoi; ToL: Tower of London Test; WCST: Wisconsin Card Sorting Test; YBOCS: Yale-Brown Obsessive Compulsive Scale

\section{Acknowledgements}

The authors would like to thank all the study participants.

\section{Authors' contributions}

AY drafts the article and substantively revised it. WA designs the work and shared in drafting of the article. AE acquisition of data and shared in the drafting of the article. SA analysis, interpretation of data and shared in the drafting of the article. All authors have read and approved the final manuscript.

\section{Funding}

The authors declare that they have no funding support.

\section{Availability of data and materials}

Not applicable

\section{Ethics approval and consent to participate}

- An official permission was obtained from Institutional Review Board at Faculty of Medicine, Zagazig University hospitals (ZU-IRB\#4021/24-92017.

- An official permission was obtained from the psychiatry department at the same University.

- A written informed consent was voluntarily sought from the participants, after clarifying of the aim of the study, methods and duration of the study. 
- Confidentiality of data was ensured and data was only be accessed by the researcher.

- Study participants had the right to withdraw from the study at any time without giving reasons and without negatively affecting their medical care.

\section{Consent for publication}

A written informed consent was voluntarily sought from the participants.

\section{Competing interests}

The authors declare that they have no competing interests.

Received: 24 November 2019 Accepted: 7 April 2020

Published online: 25 June 2020

\section{References}

1. Hosenbocus S, Chahal R (2012) A review of executive function deficits and pharmacological management in children and adolescents. J Can Acad Child Adole 21(3):223-229. https://www.ncbi.nlm.nih.gov/pmc/articles/ PMC3413474/

2. Nowrangi MA, Lyketsos C, Rao V, Munro CA (2014) Systematic Review of Neuroimaging Correlates of Executive Functioning: Converging Evidence From Different Clinical Populations. J Neuropsychiatry Clin Neurosci 26(2): 114-125. https://doi.org/10.1176/appi.neuropsych.12070176

3. Shanmugan S, Wolf DH, Calkins ME, Moore TM, Ruparel K, Hopson RD et al (2016) Common and Dissociable Mechanisms of Executive System Dysfunction Across Psychiatric Disorders in Youth. Am J Psychiatry 173(5): 517-526. https://doi.org/10.1176/appi.ajp.2015.15060725

4. Fournet N, Achachi O, Roy A, Besnard J, Lancelot C, Le Gall D et al (2019) Impaired Executive Function in Everyday Life: A Predictor of OCD Relapse? J Behav Brain Sci 9:90-107. https://doi.org/10.4236/jbbs.2019.93008

5. Shin NY, Lee TY, Kim E, Kwon JS (2014) Cognitive functioning in obsessivecompulsive disorder: A meta-analysis. Psychol Med 44(6):1121-1130. https:// doi.org/10.1017/S0033291713001803

6. Pedroli E, La Paglia F, Cipresso P, La Cascia C, Riva G, La Barbera D (2019) A Computational Approach for the Assessment of Executive Functions in Patients with Obsessive-Compulsive Disorder. J Clin Med 8:1975

7. Kim T, Kwak S, Hur J, Lee J, Shin W, Lee T et al (2019) Neural bases of the clinical and neurocognitive differences between early and late-onset obsessive-compulsive disorder. J Psychiatr Neurosci 45(1):190028. http://jpn. ca/wp-content/uploads/2019/11/45-1-190028.pdf

8. Kashyap H, Kumar JK, Kandavel T, Reddy YCJ (2013) Neuropsychological functioning in obsessive-compulsive disorder: Are executive functions the key deficit? Comprehensive Psychiatry 54:533-540. https://doi.org/10.1016/j. comppsych.2012.12.003

9. Wootton BM, Worden BL, Norberg MM, Grisham JR, Steketee G (2019) A clinician's quick guide to evidence-based approaches: Hoarding disorder. Clin Psychologist 23(1):85-87

10. Goodman WK, Price LH, Rasmussen SA, Mazure C, Fleischmann RL, Hill CL et al (1989) The Yale-Brown Obsessive Compulsive Scale. I. Development, use, and reliability. Arch Gen Psychiatry 46:1006-1011

11. Moemen DE, Abohendy WM (2006) Preparing an obsessive compulsive scale. J Psychol Studies 16:475-524

12. Diamond A (2013) Executive Functions. Annu Rev Psychol 64(1):135-168. https://doi.org/10.1146/annurev-psych-113011-143750

13. Kaller CP, Unterrainer JM, Stahl C (2012) Assessing planning ability with the Tower of London task: Psychometric properties of a structurally balanced problem set. Psychol Assess 24(1):46-53. https://doi.org/10.1037/a0025174

14. Sanz M, Molina V, Calcedo A, Martin-LoechesM RFJ (2001) The Wisconsin Card Sorting Test and the assessment of frontal function in obsessivecompulsive patients: An event-related potential study. Cog Neuropsychiatr 6(2):109-129. https://doi.org/10.1080/13546800042000089

15. Abramovitch A, Cooperman A (2015) The cognitive neuropsychology of obsessive-compulsive disorder: A critical review. J Obsessive Compulsive Relat Disord 5:4-36. https://doi.org/10.1016/j.jocrd.2015.01.002

16. Bouvard M, Fournet N, Sixdenier A, Polosan M (2018) Intrusive Thoughts and Executive Functions in Obsessive Compulsive Disorder. J Behav Brain Sci 8:399-414

17. Gonçalves ÓF, Carvalho S, Leite J, Fernandes-Gonçalves A, Carracedo A, Sampaio A (2016) Cognitive and emotional impairments in obsessive- compulsive disorder: Evidence from functional brain alterations. Porto Biomed J 1(3):92-105. https://doi.org/10.1016/j.pbj.2016.07.005

18. Page LA, Rubia K, Deeley Q, Daly E, Toal F, Mataix-Cols D et al (2018) A functional magnetic resonance imaging study of inhibitory control in obsessive-compulsive disorder. Psychiatr Res 174(3):202-209. https://doi.org/ 10.1016/j.pscychresns.2009.05.002

19. Bédard MJ, Joyal CC, Godbout L, Chantal S (2009) Executive functions and the obsessive-compulsive disorder: On the importance of subclinical symptoms and other concomitant factors. Arch Clin Neuropsychol 24(6): 585-598. https://doi.org/10.1093/arclin/acp052

20. Bannon S, Gonsalvez CJ, Croft RJ, Boyce PM (2006) Executive functions in obsessive-compulsive disorder: State or trait deficits? Aust N Z J Psychiatry 40(11-12):1031-1038. https://journals.sagepub.com/doi/full/10.1080/j.144 0-1614.2006.01928.x?url_ver=Z39.88-2003\&rfr_id=ori\%3Arid\%3Acrossref. org\&rfr_dat=cr_pub\%3Dpubmed

21. Moritz S, Birkner C, Kloss M, Jahn H, Hand I, Haasen C et al (2002) Executive functioning in obsessive-compulsive disorder, unipolar depression, and schizophrenia. Arch Clin Neuropsychol 17(5):477-483. https://doi.org/10. 1016/S0887-6177(01)00130-5

22. McNamara J, Reid A, Balkhi A, Bussing R, Storch EA, Murphy TK et al (2014) Self-Regulation and Other Executive Functions Relationship to Paediatric OCD Severity and Treatment Outcome. J Psychopathol Behav Assess 36: 432-442. https://doi.org/10.1007/s10862-014-9408-3

23. Pedron AC, Ferrão YA, Gurgel LG, Reppold CT (2015) Relations between Executive Functions and Different Symptomatic Dimensions in Obsessive Compulsive Disorder. Paidéia (Ribeirão Preto) 25:229-239. https://doi.org/10. 1590/1982-43272561201511

24. Abramovitch A, McCormack B, Brunner D, Johnson M, Wofford N (2019) The impact of symptom severity on cognitive function in obsessive-compulsive disorder: A meta-analysis. Clin Psychol Rev 67:36-44. https://doi.org/10.1016/ j.cpr.2018.09.003

25. Airaksinen $E$, Larsson M, Forsell $Y$ (2005) Neuropsychological functions in anxiety disorders in population-based samples: evidence of episodic memory dysfunction. J Psychiatr Res 39:207-214. https://doi.org/10.1016/j. jpsychires.2004.06.001

26. Suhas S, Rao NP (2019) Neurocognitive deficits in obsessive-compulsive disorder: A selective review. Indian J Psychiatry 61:30-36

27. Krishna R, Udupa S, George CM, Kumar KJ, Viswanath B, Kandavel T et al (2011) Neuropsychological performance in OCD: A study in medicationnaïve patients. Prog Neuropsychopharmacol Biol Psychiatry 35:1969-1976

28. Rosenblat JD, Kakar R, McIntyre RS The cognitive effects of antidepressants in major depressive disorder: A systematic review and meta-analysis of randomized clinical trials. Int J Neuropsychopharmacol 19

29. Purcell R, Maruff P, Kyrios M, Pantelis C (1998) Neuropsychological deficits in obsessive-compulsive disorder: A comparison with unipolar depression, panic disorder, and normal controls. Arch Gen Psychiatry 55:415-423

30. Abramovitch A, Abramowitz JS, Mittelman A (2013) The neuropsychology of adult obsessive-compulsive disorder: A meta-analysis. Clin Psychol Rev 33: 1163-1171

31. Rao NP, Reddy YC, Kumar KJ, Kandavel T, Chandrashekar CR (2008) Are neuropsychological deficits trait markers in OCD? Prog Neuropsychopharmacol Biol Psychiatry 32:1574-1579

32. Moritz S, Birkner C, Kloss M, Jacobsen D, Fricke S, Böthern A et al (2001) Impact of comorbid depressive symptoms on neuropsychological performance in obsessive-compulsive disorder. J Abnorm Psychol 110:653657. https://doi.org/10.1037/0021-843X.110.4.653

\section{Publisher's Note}

Springer Nature remains neutral with regard to jurisdictional claims in published maps and institutional affiliations. 